\title{
Quality assessment of high density digital surface model over different land cover classes
}

\author{
IVAN BALENOVIĆ ${ }^{1}$ \\ HRVOJE MARJANOVIĆ 1 \\ DIJANA VULETIĆ 2 \\ ELVIS PALADINIĆ 1 \\ MAŠA ZORANA OSTROGOVIĆ SEVER ${ }^{1}$ \\ KRUNOSLAV INDIR ${ }^{3}$ \\ ${ }^{1}$ Croatian Forest Research Institute \\ Division for Forest Management \\ and Forestry Economics, Trnjanska cesta 35 \\ HR-10000 Zagreb, Croatia \\ ${ }^{2}$ Croatian Forest Research Institute \\ Cvjetno naselje 41, HR-10450 Jastrebarsko \\ Croatia \\ ${ }^{3}$ Croatian Forest Research Institute \\ Division for Forest Management \\ and Forestry Economics, Vilka Novaka 50c \\ HR-42000 Varaždin, Croatia
}

\section{Correspondence: \\ Ivan Balenović \\ E-mail: ivanb@sumins.hr}

Keywords: digital surface model (DSM), digital stereo aerial images, image matching, vertical agreement assessment, forest inventory, Croatia
Received July 4, 2015.

Revised January 21, 2016.

Accepted January 21, 2016.

\begin{abstract}
Background and Purpose: Recent research on generation of digital surface models (DSMs) using image matching methods revealed a great potential of DSM application in forestry, especially in forest inventory. However, research dealing with DSM generation from digital aerial images are still lacking in Croatia. Therefore, the main objective of this study was to present the workflow for generating high density DSM from colour infrared (CIR) digital stereo aerial images using area-based image matching algorithm.

Materials and Methods: The high density DSM was generated from colour infrared digital aerial stereo images using Dense DTM algorithm of PHOTOMOD software - an area-based image matching algorithm which operates on the principle of cross-correlation approach. To evaluate the quality of the generated DSM, an agreement assessment with manual stereo measurements was conducted over three different land cover classes (forests, shrubs, grasslands) using the same images as for DSM generation.
\end{abstract}

Results: The good vertical agreement between the generated DSM and stereo measurement was achieved for all three land cover classes present at the research area. The highest vertical agreement was obtained for the grassland land cover class (RMSE $=0.36$ ), slightly lower for forest ( $R M S E=0.62)$, whereas the lowest vertical agreement was obtained for shrub land cover class (RMSE=0.83).

Conclusions: The results of this research are very promising and suggest that the high density DSM generated from digital aerial stereo images and by using the proposed methodology has the potential to be used in forestry, primarily in forest inventory. Therefore, further research should be focused on generation of CHM by subtracting available DTM from the high density DSM and on the examination of its potential for deriving various forest attributes.

\section{INTRODUCTION}

Dhotogrammetry is a typical engineering discipline that is greatly influenced by developments in computer science and electronics (1). This has become especially evident over the past thirty years during which photogrammetry has gone through transition from analogue, over analytical to digital photogrammetry $(1,2)$. During this development period, analogue aerial photographs as well as analogue and analytical stereo instruments have been replaced with digital aerial images and digital photogrammetric workstations $(3,4)$. Current digital aerial photogrammetric cameras are capable of capturing digital aerial images of very high spatial resolution with ground sampling distance (GSD) of only several centimetres (5). In addition, the radiometric resolution of 
digital images is superior in comparison to the resolution of analogue photographs (6). Such quality digital images in combination with digital photogrammetric workstations have led to automation, facilitation and improvements in performance of many demanding photogrammetric procedures (aerial triangulation, digital terrain models generation, orthophoto generation, etc.) $(7,8)$. The automation in digital photogrammetry is based on stereo photogrammetric processing called image matching, also referred to as image correlation (9). The aim of image matching is to find corresponding points in two or more stereo images based on their radiometric and geometric similarity (10). The result of image matching is image $3 \mathrm{D}$ point cloud which is then used to generate digital terrain model (DTM) which represents the elevation of the Earth's terrain (bare ground) or digital surface model (DSM) which represents the elevation of the Earth's surface including the human-made (e.g. buildings) or natural (e.g. trees) features.

In recent years, the automatic DTM and DSM generation through image matching has encountered great interest among the researchers worldwide (11). Various image matching algorithms and photogrammetric software packages have been developed and have become commercially available (11). The main image matching methods, which are: (i) area-based, (ii) feature-based, and (iii) combination of area- and feature-based methods, were summarized and described by White et al. (10). According to St-Onge et al. (12), stereo matching parameters, image resolution, and differences in sun-angle and viewing geometry have a great impact on the quality of image matching procedure and DSM generation, regardless of the method used. Baltsavias et al. (11) stated that all image matching methods encounter similar problems in DTM/DSM generation (e.g. little or no texture; distinct object discontinuities; object with no flat surface; repetitive objects; occlusions; moving objects, including shadows; multi-layered and transparent objects, radiometric artefacts like specular reflections and others; etc.). In forestry applications, due to complex forest structure, these issues may cause even greater problems in image matching procedure and DSM generation. Namely, image matching methods must be able to adapt to very steep variations in height (13). Furthermore, since the images are greatly influenced by solar elevation and view angles, occlusions and shadows in forest canopy may have serious influence on the quality of image matching procedure (10, $12,14,15)$. During windy weather, the bending of trees can also be problematic (16). Due to all these factors, the accuracy of a DSM over forest area is usually lower than over bare land (17) or grassland (18). However, some of above mentioned factors may be limited or reduced by conducting aerial surveys in the proper time of the day and during the favourable weather conditions.

Recent research on DSM generation using image matching methods revealed a great potential of DSM ap- plication in forestry, especially in forest inventory (e.g. $11-13,19-25)$. In forestry application, DSM is usually used in combination with DTM derived from image point clouds or airborne laser scanning (ALS) data. Namely, by subtracting DTM from the corresponding DSM, canopy height model (CHM) can be generated and could serve as a basis for deriving various forest attributes (26).

Starting from 2009, the regular national aerial surveys in Croatia using digital aerial cameras were conducted three times $(2009,2011,2015)$. That means that the whole country is covered by digital aerial images of high spatial resolution with GSD of $20-30 \mathrm{~cm}$ captured during the leaf-on season. Additionally, DTM for the whole country generated from breaklines and mass points collected by stereo mapping of the digital aerial images was also available. Both digital aerial images and DTM can be obtained from the Croatian State Geodetic Administration.

Despite the availability of these data, to date, in Croatia there have been no studies which deal with DSM generation from digital stereo aerial images using image matching methods. Therefore, the main objective of this study was to present the workflow for generating high density DSM from colour infrared (CIR) digital stereo aerial images using area-based image matching algorithm. Furthermore, to evaluate the quality of the generated DSM, an agreement assessment with manual stereo measurement was conducted over three different land cover classes (forests, shrubs, grasslands). Finally, the potential of DSM for application in Croatian forestry was discussed and future research directions were presented.

\section{MATERIALS AND METHODS}

\section{Study area}

The study area is located near the municipality of Pisarovina, $25 \mathrm{~km}$ south of Zagreb, Croatia ( $45^{\circ} 33^{\prime} \mathrm{N}$, $15^{\circ} 54^{\prime}$ E - Transverse Mercator projection, Bessel 1841 ellipsoid, Helmannskoegel datum) (Figure 1). The total size of the study area is approximately 380 ha, whereas about 180 ha are covered by the privately owned forest of management unit Donja Kupčina - Pisarovina. The main tree species are sessile oak (Quercus petraea L.), European beech (Fagus sylvatica L.), common hornbeam (Carpinus betulus L.) and black alder (Alnus glutinosa (L.) Gaertn.), forming even-aged (sessile oak management class) and the multi-aged stands (European beech and common hornbeam management classes). Due to the absence of proper and regular management of forests in the past, the majority of the forests in the study area are of heterogenic structure. Other land cover classes present at the study area are more or less used agricultural land (arable land, pastures, meadows), abandoned agricultural land overgrown by shrubs, grasslands, small built up areas (small settlements, roads), and small water surfaces (streams and canals). The altitude of the area ranges from 105 to $160 \mathrm{~m}$ and slope from $0^{\circ}$ to $30^{\circ}$. 


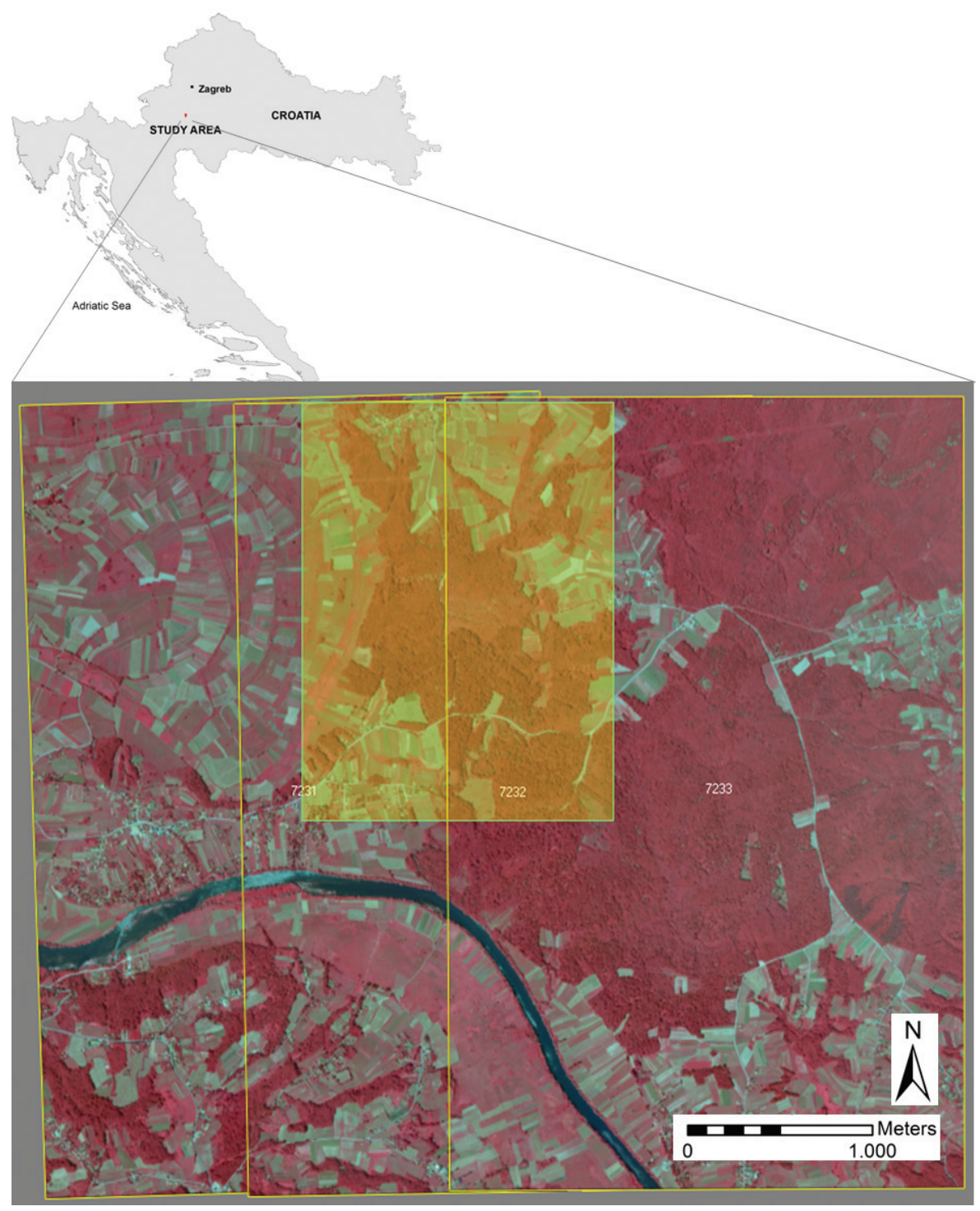

Figure 1. Location of the study area (small figure, top left). Image block of the colour infrared digital aerial stereo images (main figure). The yellow shaded rectangle in the image block presents the area selected for digital surface model (DSM) generation.

\section{Digital aerial images}

The colour infrared (CIR) digital stereo aerial images of the study area were collected using a Microsoft UltraCamX digital large-format aerial camera (Vexcel Imaging $\mathrm{GmbH}$, a Microsoft Company, Graz, Austria) by Geofoto Ltd. (Zagreb, Croatia). The images were collected as a part of the regular national aerial survey of the Croatian State Geodetic Administration in 2009. The UltraCamX is a multi-head camera consisting of eight camera heads. Four camera heads equipped with nine individual CCD sensors build large format panchromatic images by recording the visible part of the electromagnetic spectrum. Another set of four camera heads with individual CCD sensors collect the multispectral data, i.e. colour information in the blue $(445-515 \mathrm{~nm})$, green $(510$
$590 \mathrm{~nm})$, red (600-680 nm), and near infrared (710-830 $\mathrm{nm})$ bands of the spectrum. The high-resolution multispectral images (image size of 14,430 by 9,420 pixels; pixel size of $7.2 \mu \mathrm{m}$; radiometric resolution $>12 \mathrm{bit}$ ) are provided by pan-sharpening lower resolution multispectral data in post-processing. The camera has a principal distance of $100.5 \mathrm{~mm}$, and provides a field of view of $55^{\circ}$ and $37^{\circ}$ in cross track and along track directions, respectively (27).

The aerial survey was conducted during leaf-on conditions on July 22, 2009. The average flying height was $4,190 \mathrm{~m}$ above ground level, resulting in a ground sampling distance (GSD) of $30 \mathrm{~cm}$. The study area was covered by three CIR images from a single strip with forward overlaps of $60 \%$ and side overlaps of $30 \%$ (Figure 1). The 
base of acquired images was $1130.4 \mathrm{~m}$, which resulted in a base-to-height ratio of 0.26 . The images were collected between 11:30 am and 02:00 pm local time $(\mathrm{UTC}+1)$ when the weather conditions were good (clear sky, no wind) and the solar elevation angle was $55-65^{\circ}$.

During aerial survey a computer-controlled system for operating the camera CCNS4 (Computer Controlled Navigation System, 4th generation; IGI mbH, Kreuztal, Germany) was used, whereas the precise position of projection centres and exterior orientation parameters of aerial images were recorded using a GPS and an inertial navigation system, GPS/IMU AEROcontrol (IGI mbH, Kreuztal, Germany).

The collected raw image data were post-processed (radiometric and geometric correction, pan-sharpening) using the camera specific Microsoft Office Processing Center software (Microsoft, Vexcel Imaging $\mathrm{GmbH}$, Graz, Austria). The original radiometric resolution (12 bit) of the images was resampled to 8 bit resolution. The post-processed images were then introduced into an aerial triangulation performed by the ImageStation Automatic Triangulation software module (Intergraph Corporation, Huntsville, Alabama, USA). The orientation (adjustment) accuracy of aerial triangulated images validated with 15 ground control points, in terms of root mean square error (RMSE), was $0.121,0.088$, and 0.020 $\mathrm{m}$ in the $\mathrm{x}, \mathrm{y}$, and $\mathrm{z}$ directions, respectively. The images' post-processing and aerial triangulation were done by Geofoto Ltd (Zagreb, Croatia). Along with CIR images (8-bit radiometric resolution, $30 \mathrm{~cm}$ GSD), the data provided to us were the interior and exterior orientation parameters.

\section{Digital photogrammetric workstation (DPW)}

The digital photogrammetric workstation (DPW) is a combination of powerful hardware and software components designed to carry out demanding photogrammetric procedures (e.g. aerial triangulation, image matching, ortorectification, stereo visualization, etc.) and derive photogrammetric products (e.g. DTM, DSM, CHM, DOP, digital maps, 3D vector data, etc.) from digital images using manual and automated techniques (28). Apart from fast processor (CPU), large memory (RAM) and large storage capacity (HDD), the essential part of the DPW's hardware is the stereo viewing system consisting of a graphic card and a display system (high resolution stereo monitor and stereo glasses) (29). Recommended configuration of the DPW needed for comfortable work with PHOTOMOD 5.24 software, as well as the configuration used in this research are shown in Table 1.

The software component of DPW consists of PHOTOMOD 5.24 digital photogrammetric system (Racurs Co., Moscow, Russia) and QGIS 2.12 open source geographic information system (QGIS Development Team). PHOTOMOD 5.24 is a modular system providing a full photogrammetric production line from the project creation, aerial triangulation to output products (digital terrain models, vector maps, orthomosaics, etc.). Within this research the following PHOTOMOD modules were used: (i) PHOTOMOD Core, the core module used to create and manage projects; (ii) PHOTOMOD AT for image orientation; (iii) PHOTOMOD DTM used for DSM generation, and (iv) PHOTOMOD StereoDraw used for stereo measurements to obtain reference data (stereo measurements points) for the agreement assess-

TABLE 1. The hardware and software configuration of the digital photogrammetric workstation (second column - recommended configuration for comfortable work with PHOTOMOD 5.24, third column - configuration used within this research).

\begin{tabular}{|lll|}
\hline Component & Recommended & Used \\
\hline Hardware & & \\
Central processing unit (CPU) & Intel Core 2 Quad 3 GHz or equivalent & Intel $^{\circ}$ Core $^{\mathrm{Tm}}$ i7-3770 CPU 3.40 GHz \\
System memory (RAM) & 4 GB for Win64 & $8 \mathrm{~GB}$ \\
System type & - & 64-bit Operating System \\
Hard disk drive (HDD) & IDE / SATA 1000 GB & ST1000DM003 1000 GB \\
Graphic card & Based on NVIDIA Quadro FX 570 or higher & NVIDIA Quadro K2000 \\
Display system & StereoPixel LcReflex-20 3D-monitor, Samsung Syncmaster & ACER Predator GN246HL stereo monitor. \\
Manipulators & 2233RZ or equivalent with ability to work at a 120Hz frequency & NVIDIA 3D Vision glasses kit. \\
Software & & Conventional mouse and keyboard \\
Operating system & Microsoft Windows 7 & \\
PHOTOMOD 5.24 & & Microsoft Windows 7 Professional \\
QGIS 2.12 & & Digital photogrammetric system \\
\hline
\end{tabular}


ment of DSM. Upon finished photogrammetric part of research and obtaining spatial data (DSM, stereo measurement points), QGIS software was used for additional data processing and analysis.

\section{Image pre-processing}

An overview of the methodological workflow of the image pre-processing and DSM generation is shown schematically in Figure 2.

Prior to photogrammetric processing (e.g. DSM generation, stereo measurements), the obligatory step is image pre-processing consisting of project creation, the forming of images block and image orientation (aerial triangulation, block adjustment).

The project was created (specifying project type and name, choosing coordinate system) and the block consisting of three overlapping stereo images was formed (adding images into a block, positioning/rotation of images in the block) using PHOTOMOD Core module.

Since the images were previously aerial triangulated, the image/block orientation was performed by defining (loading) interior and exterior orientation parameters in
PHOTOMOD AT module. Both interior and exterior orientation parameters were provided to us along with the images. The first step of the image/block orientation was interior orientation $(\mathrm{IO})$ which defines the internal geometry of a camera as it existed at the time of data capturing. It is primarily used to transform the image pixel coordinate system to the image space coordinate system (30). When performing the IO, two sets of parameters have to be considered: (i) geometric camera parameters (pixel size, focal length, principal point coordinates) and (ii) parameters of systematic errors (e.g. lens distortion) (31). IO parameters are usually available to the user in camera's calibration report. Since in the calibration report of the UltraCamX camera it was reported that the remaining lens distortion is less than $0.002 \mathrm{~mm}$, the $\mathrm{IO}$ was performed based on geometric camera parameters. The next step was the exterior orientation (EO) which describes the transformation between the image and the object coordinate system (32), i.e. defines the position and angular orientation of the camera while capturing the image (30). To conduct EO, parameters recorded by GPS/IMU onboard system were used. EO parameters are the coordinates of projection centres $(x, y, z)$ and three rotation

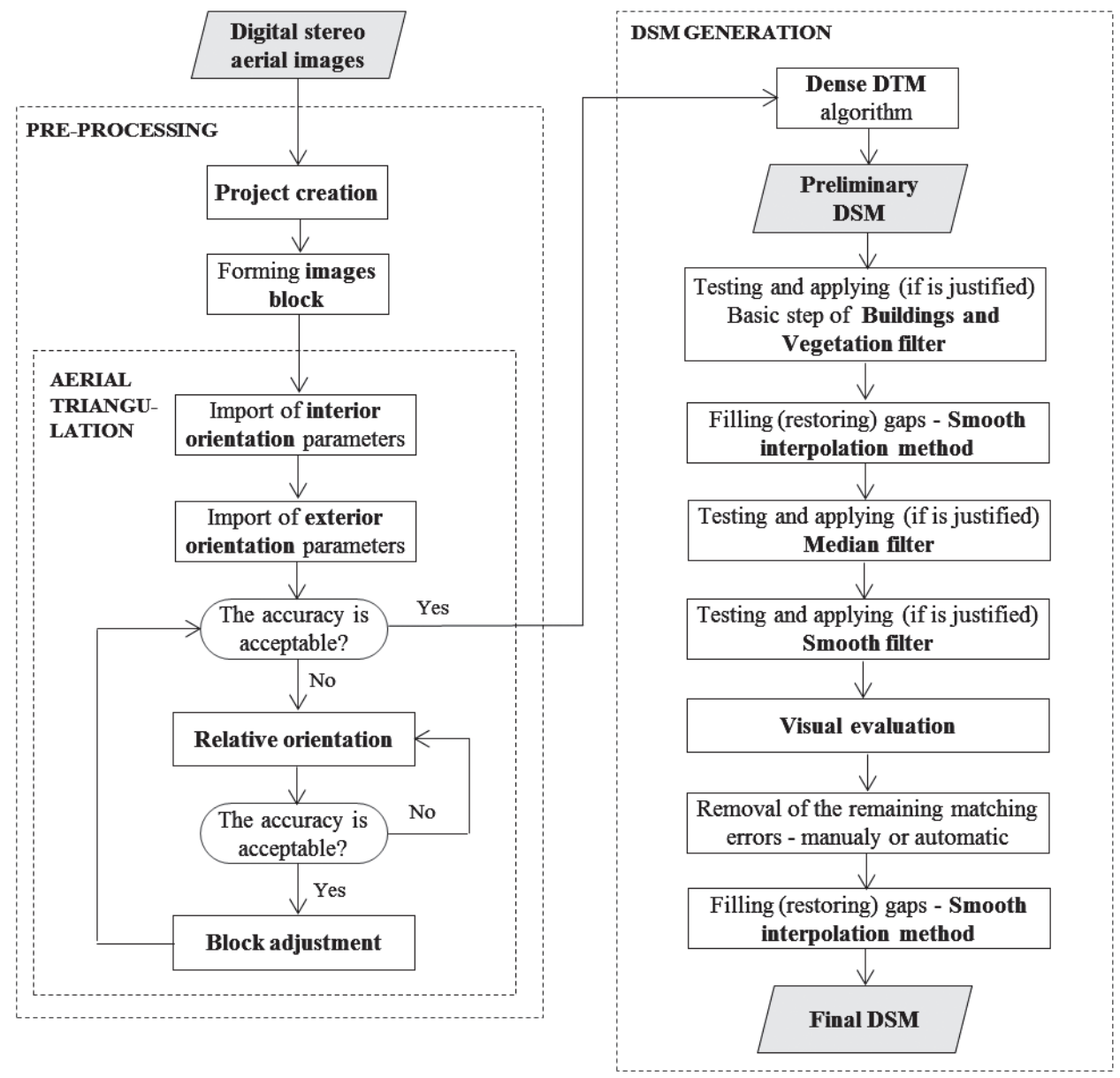


angles $(\omega, \varphi, \kappa)$ that together define the position and angular orientation of images at the time of capture.

If the accuracy of imported exterior orientation parameters is satisfying, which was in this case, photogrammetric processing in terms of DEM generation and stereo measurements can be continued. As already stated, the orientation (adjustment) accuracy of the previously aerial triangulated images in terms of RMSE was 0.121, 0.088, and $0.020 \mathrm{~m}$ in the $\mathrm{x}, \mathrm{y}$, and $\mathrm{z}$ directions, respectively. Otherwise, if orientation accuracy after IO and EO is not satisfying, the relative orientation, i.e. a more precise images location in space by automatic or manually adding of new tie points, and block adjustment should be performed.

\section{Generation of the digital surface model (DSM)}

Prior to DSM generation, the DSM area was specified by the creation of a grid over three overlapping stereo images. For DSM generation, a Dense DTM algorithm of PHOTOMOD DTM module was used. Dense DTM is area-based image matching algorithm which calculates the coordinates of conjugate points between overlapping images for each pixel of the selected area using crosscorrelation approach. The resolution (pixel size) of gener- ated DSM (image based point cloud), thus, corresponds to image pixel size, which was in this case $0.2972 \times 0.2972$ $\mathrm{m}$. The initial, preliminary DSM was generated using predefined basic and additional correlator parameters' settings (Table 2).

To remove matching errors in the DSM, i.e. spikes (points above or below surface), additional filtering of initial DSM using Buildings and vegetation (BV) filter was performed. While removing spikes only Basic filter (first step) of BV filter is used. The parameters of Basic filter that should be applied are: (a) thinout coefficient for calculating basic points, (b) near and far distance of mutual points influence, and (c) threshold slope angle for spikes. The option 'Spikes only' should be chosen. A number of different parameters settings were applied on a several small test areas to evaluate spikes removal from the initial DSM. Based on visual evaluation, the most suitable combination of parameters of BV filter was applied to remove spikes from initial DSM (Table 2). The resulting gaps (null cells) were then filled (restored) by smooth interpolation method. This method is recommended for the sufficiently dense DSM. The computation of the heights is carried out exclusively for the null cells, i.e. the known heights of the input DSM cells are not changed.

TABLE 2. Parameters of Dense DTM algorithm used for DSM generation

\begin{tabular}{|c|c|c|}
\hline Parameter & Value & Description \\
\hline \multicolumn{3}{|c|}{ (a) Basic correlator parameters } \\
\hline Check area & $4 \times 1$ & The size of search matrix \\
\hline Correlation threshold & 0.2 & Minimum accepted correlation coefficient value for matched pixels of images \\
\hline Autocorrelation radius & 20 & Used to control point's autocorrelation - degree of point's uniqueness in some its vicinity on the left image \\
\hline \multicolumn{3}{|c|}{ (b) Additional correlator parameters } \\
\hline Images smoothing & $\max$ & Define a level of images smoothing \\
\hline Search by $\mathrm{X}$ & $12 \times 12$ & Search area size by $\mathrm{X}$ with respect to the approximation calculated considering orientation data \\
\hline Search by Y & $3 \times 3$ & Search area size by $\mathrm{Y}$ with respect to the approximation calculated considering orientation data \\
\hline Mask halfsize & 10 & Half of linear size of rectangular correlation mask in pixels by $\mathrm{X}$ and $\mathrm{Y}$ axes \\
\hline Micro tile size & 100 & Area size in microtile used to match pixels \\
\hline Macro tile size & 512 & Size of image area \\
\hline Coarse threshold & 0.2 & A value of correlation coefficient during microtiles matching \\
\hline Dispersion threshold & 5 & A value of contrast during matching of images pixels \\
\hline Image subsampling factor & & Used level of image pyramid for points search \\
\hline \multicolumn{3}{|c|}{ (c) Buildings and vegetation filter parameters } \\
\hline $\begin{array}{l}\text { Thinout coefficient for } \\
\text { calculating basic points }\end{array}$ & 6 & $\begin{array}{l}\text { From the specified value and the source DEM cell size parameter depends the space between basic } \\
\text { points parameter in meters }\end{array}$ \\
\hline $\begin{array}{l}\text { Near and far distance of } \\
\text { mutual points influence }\end{array}$ & $\begin{array}{l}\text { Near }=6 \\
\text { Far }=152\end{array}$ & Define the radius of the circle, in which the values of pickets are analysed for errors \\
\hline $\begin{array}{l}\text { Threshold slope angle for } \\
\text { spikes }\end{array}$ & $\begin{array}{l}\mathrm{Up}=45 \\
\text { Down }=45\end{array}$ & $\begin{array}{l}\text { Specify angle of slope in relation to selected measuring plane (above and/or below surface) to define } \\
\text { sharp spikes }\end{array}$ \\
\hline
\end{tabular}


The next step in DSM generation was testing the applicability of both Median and Smooth filters for DSM enhancement which was conducted on the same small test areas used for testing BV filter parameters. In this case, none of the applied parameters' combinations of both filters resulted with changes (improvements) on DSM, and therefore these filters have not been used for DSM improvements.

Finally, DSM was visually evaluated and matching errors (spikes) not removed by BV filter were manually repaired by cutting polygons and filling null cells using smooth interpolation method.

\section{Reference data for agreement assessment of DSM}

To evaluate the quality of the generated DSM, the procedure of agreement assessment similar to Hoby and Ginzler (18) and Ginzler and Hoby (33) using stereo measurement as a reference data was applied. The manual stereo measurement was conducted in a PHOTOMOD StereoDraw module on nodes (points) of a regularly 150 $\mathrm{m}$ sampling grid using the same images as for DSM generation (Figure 3). A photo interpreter measured the elevation of each point by placing a stereo marker on the surface and creating a 3D point object. In addition, land cover classes were assigned to each stereo measured (SM) point. For that purpose, three land cover classes were dis-

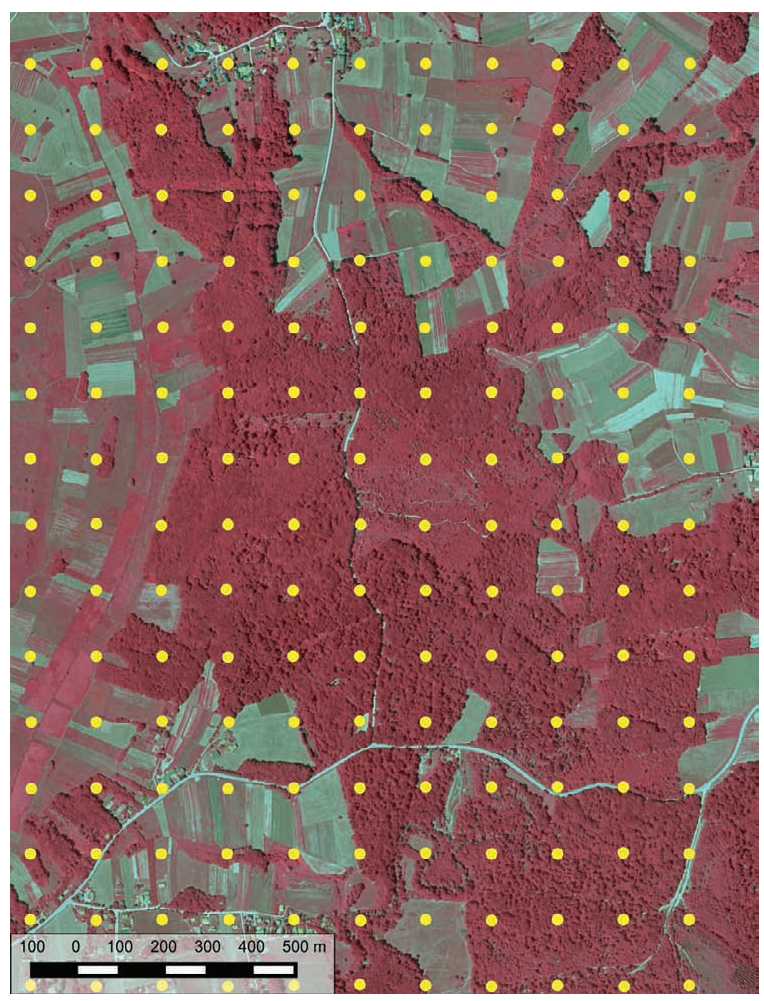

Figure 3. Reference data (stereo measured points) for vertical agreement assessment of digital surface model (DSM) tinguished in the study area: (i) forest, (ii) shrub vegetation (including solitary trees or small group of trees), and (iii) grassland vegetation (including agricultural land with no crops or with low height crops). A total of 165 SM points were recorded by stereo measurement, 56 of which were recorded over forests, 41 over the shrub vegetation, and 68 over the grass vegetation.

\section{Analysis - agreement assessment}

The ground checkpoints are the most common reference data set used for the accuracy assessment (quality control) of the DSM (34). Since within this research the ground checkpoints were not available to us, we used only stereo measurements (SM points) as a reference data for the DSM quality control. According to Ginzler and Hoby (33), the data obtained through stereo measurements are highly suitable for the vertical agreement assessment with the DSM over different land cover classes, but cannot be used for an absolute accuracy assessment. Therefore, within this research only assessment of DSM vertical agreement with stereo measurements was carried out.

The vertical agreement assessment of the DSM was conducted by comparing elevations of SM points and planimetrically corresponding DSM points. It is very often the case that DSM errors are not normally distributed due to e.g. filtering and interpolation errors in non-open areas (e.g. forests) (34). Höhle and Höhle (34) suggest different accuracy measures for DSMs with normal and those with non-normal error's distribution. Therefore, prior to applying any agreement assessment measures, differences between DSM and SM points were calculated and the normality of the distribution of errors was tested. The normality was checked using Shapiro-Wilk test (35, 36) which revealed that DSM errors were normally distributed $(\mathrm{p}<0.05)$ (Figure 4). Consequently, and as suggested by Höhle and Höhle (34), the following measures were used for agreement assessment of the generated DSM with reference data (stereo measurement): root mean square error (RMSE), mean error $(\mu)$, and standard deviation error $(\sigma)$. The equations to calculate these errors are the following:

$$
R M S E=\sqrt{\frac{\sum_{i=1}^{n}\left(\bar{z}_{i}-z_{i}\right)^{2}}{n}}
$$

$$
\mu=\frac{\sum_{i=1}^{n}\left(\bar{z}_{i}-z_{i}\right)}{n}
$$

$$
\sigma=\sqrt{\frac{\sum_{i=1}^{n}\left(\left(\bar{z}_{i}-z_{i}\right)-\mu\right)^{2}}{n-1}}
$$


where $\bar{z}_{i}$ is the elevation of the DSM exported from point $i, z_{i}$ is the elevation of reference data (SM points) estimated on point $i$, and $n$ is the number of points.

The agreement assessment measures were calculated for the whole DSM area, as well as for the each land cover class (forests, shrubs, grasslands). Data were analyzed using the program STATISTICA 7.1 (37).

\section{RESULTS AND DISCUSSION}

\section{Workflow of DSM generation}

The entire workflow of the presented methodology, from image orientation to high density DSM generation, is highly automated. The applied Dense DTM algorithm of PHOTOMOD software utilises the performance of powerful graphic card (NVIDIA Quadro K2000) for cross-correlation image matching procedure resulting in a generation of a high density DSM with pixel size that corresponds to image pixel size $(0.2972 \mathrm{~cm})$.

It is generally known that DSM quality is lower in shadow areas and near the forest boundary $(10,12,38$, 39, 40). Visual assessment of preliminary DSM revealed matching errors mostly caused by shadows in images near the forest boundaries or in the forest parts with bigger gaps between the crowns. These matching errors appear in preliminary DSM as spikes, small areas with considerably lower elevations than the surrounding area, and therefore they were easily noticeable. The shadows in the images occur as a consequence of the camera view angle, terrain topography and sun elevation $(12,13,41)$. To limit the extent and proportion of shadows, aerial images are usually collected within two hours of solar noon (42, 43). Since the images used in this research were collected between 11:30 am and 02:00 pm local time when the solar elevation angle was $55-65^{\circ}$, the influence of shadows on image matching were limited to minimum.

To enhance preliminary generated DTM, i.e. to reduce/remove matching errors several filters provided by PHOTOMOD software may be used. However, each of the filters requires a number of parameters to be applied. Therefore, prior to the application of any filter it is recommended to conduct preliminary tests with different parameter settings. In our case, preliminary tests conducted on several small test areas revealed that only Basic filter (first step) of BV filter with appropriate combination of parameters reduce matching errors, whereas the application of Smooth and Median filter did not enhance (improve) preliminary DSM.

After applying BV filter, most of the matching errors were removed. Finally, DSM was visually evaluated and the matching errors (spikes) not removed by BV filter were manually repaired by cutting polygons and filling null cells using smooth interpolation method. Only in this last step of DSM generation, the manual method was used. This was possible because the generated DSM covers a small area (380 ha) and because of the relatively small number of spikes left for removal after applying BV filter. However, in the case when greater amount of spikes distributed over the DSM of larger area should be removed it is recommended to use some of the available automated filtration methods.

Based on visual assessment it seems that DSM was successfully generated (Figure 5). All land cover classes (forests, shrubs, grasslands) are very well represented, so even small individual shrubs or individual trees could be visually determined. However, to further characterize the quality of the generated models, vertical agreement assessment of DSM was conducted using reference data.

\section{Agreement assessment of DSM}

The vertical agreement assessment of DSM was carried out using stereo measured (SM) points, distributed in a regular $150 \mathrm{~m}$ sampling grid. From a total of a $165 \mathrm{SM}$ points, 56 were recorded over forests, 41 over shrub vegetation, and 68 over the grass vegetation. A preliminary evaluation (Shapiro-Wilk test) revealed that DSM errors (differences between elevations of DSM and SM points) were normally distributed $(\mathrm{p}<0.05)$ (Figure 4). Therefore, standard measures (RMSE, $\mu, \sigma$ ) were used to evaluate DSM quality (Table 3). The highest agreement values, i.e.

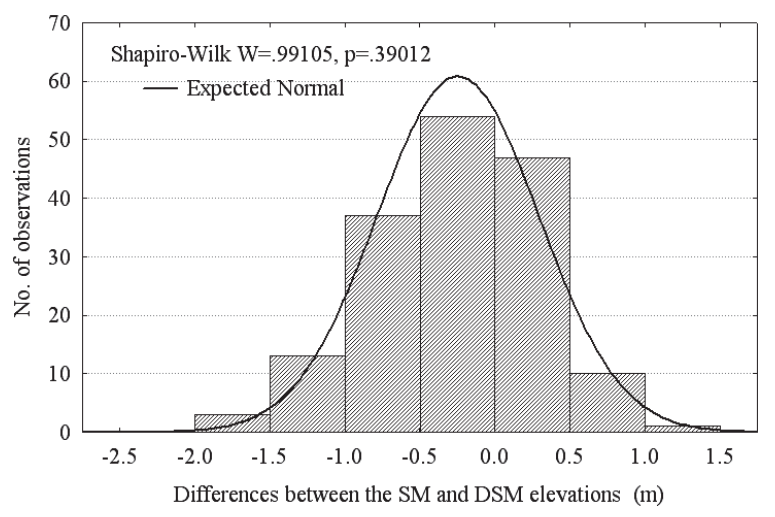

Figure 4. A histogram of the differences between the elevations obtained by stereo measurements (SM points) and elevations extracted from planimetrically corresponding DSM points

TABLE 3. The vertical agreement of DSM with stereo measurements (SM points) calculated for three land cover classes and for the entire DSM area

\begin{tabular}{|cccc|c|}
\hline Land cover class & Sample size & RMSE $(\mathrm{m})$ & $\mu(\mathrm{m})$ & $\sigma(\mathrm{m})$ \\
\hline Grasslands & 68 & 0.36 & -0.01 & 0.37 \\
Forests & 56 & 0.62 & -0.45 & 0.44 \\
Shrubs & 41 & 0.82 & -0.37 & 0.73 \\
Total & 165 & 0.59 & -0.25 & 0.54 \\
\hline
\end{tabular}

RMSE - root mean square error

$\mu$-standard error

$\sigma-$ standard deviation 

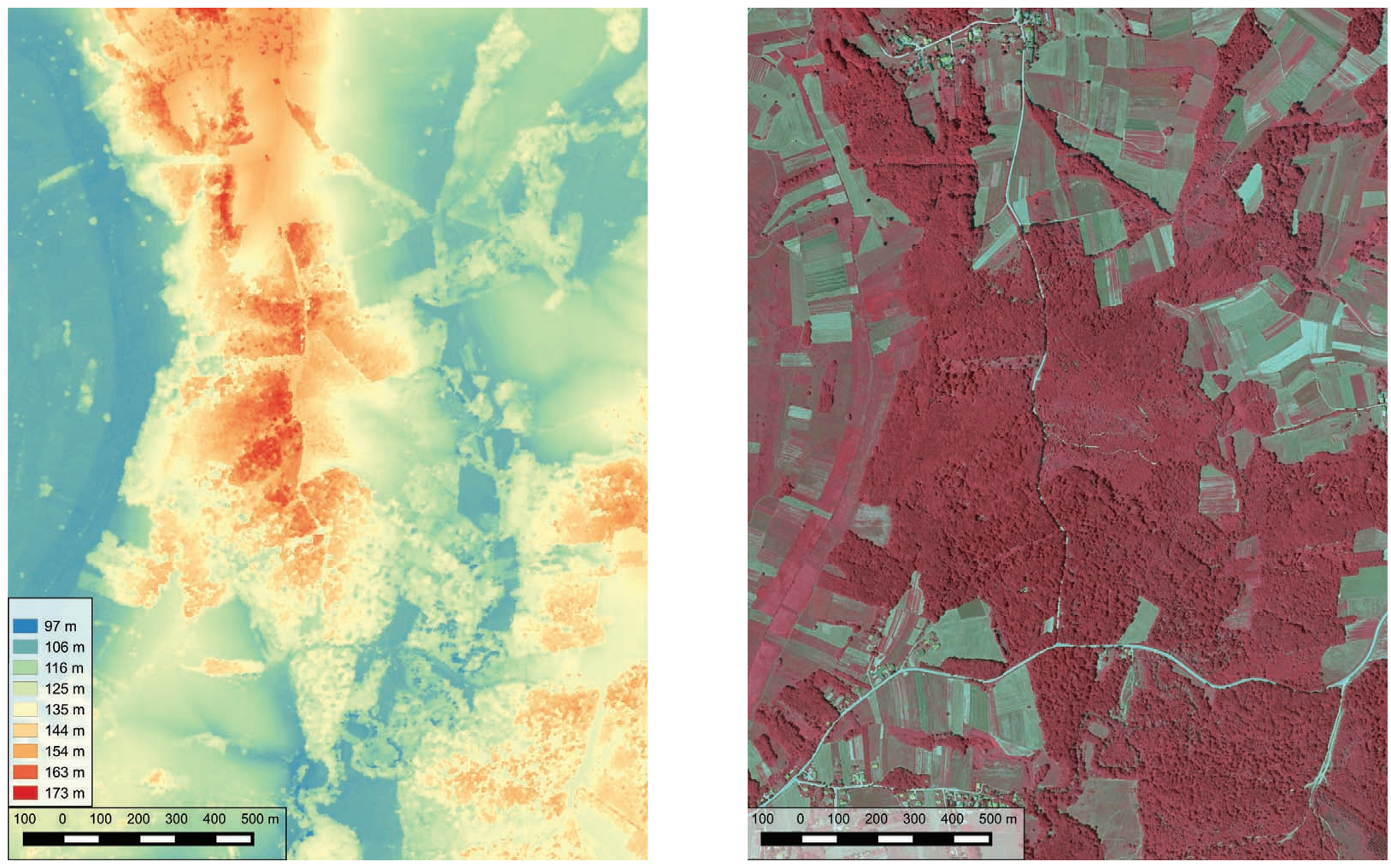

Figure 5. The generated high density digital surface model (left) and the corresponding area shown in digital aerial images (right)

the lowest RMSE, $\mu$ and $\sigma$ values were obtained for grassland land cover class which includes agricultural land with no crops or with low height crops. On the contrary, the generated DSM produced the lowest vertical agreement with SM points for shrub land cover class. This was expected because this land cover class is consists of very heterogenic vegetation: low or high shrubs with solitary trees or a small group of trees. As a consequence, the parts of images with shrub cover class may have big variations in height on a relatively small area and a greater share of shadows which in turn hinders the image matching procedure $(21,39)$ and results in the lower accuracy of the generated DSM. In comparison to shrub land cover class, slightly better vertical agreement of DSM was obtained for forest land cover class.

The results of this research are therefore in accordance with other studies $(17,18,33)$ which showed that the DSM accuracy depends on land cover class. For example, Hoby and Ginzler (18) evaluated DSM agreement with stereo measurements over three land cover classes (grass and herb vegetation, forested areas, artificial areas) and found the lowest DSM agreement for forest areas.

The calculated negative values of standard errors ( $\mathrm{Ta}$ ble 3) indicate that elevations extracted from DSM are slightly underestimated compared to the elevations obtained by stereo measurements (SM points), especially for forest and shrub land cover class. This is also confirmed by graphs showing differences between elevations from DSM and elevations of SM points per land cover class and for the entire DSM area (Figure 6). Baltsavias et al. (11) stated that photogrammetric DSM generated from aerial images will always have a tendency to slightly underestimate forest surface, due to the surface smoothing that occurs during image matching. However, compared to SM points, the underestimations of the forest surface by DSM do not exceed over $-1.15 \mathrm{~m}$ (Figure 6).

\section{Future research directions}

The results of this research are promising and suggest that the high density DSM generated from high resolution aerial stereo images and by using the proposed methodology has the potential to be used in forestry. Namely, the vertical agreement of the generated DSM with stereo measurements over the forest was very good (Table 3). However, to confirm the reliability of the DSM generated using the proposed methodology, the absolute accuracy (vertical and horizontal) of the DSM should be also analysed by using ground checkpoints.

Furthermore, future research should be focused on CHM generation by subtracting available DTM from the corresponding DSM and by examination of its potential for deriving various forest attributes. As it was already mentioned, photogrammetric DTM generated by stereomapping of the digital aerial images is available in Croatia. 

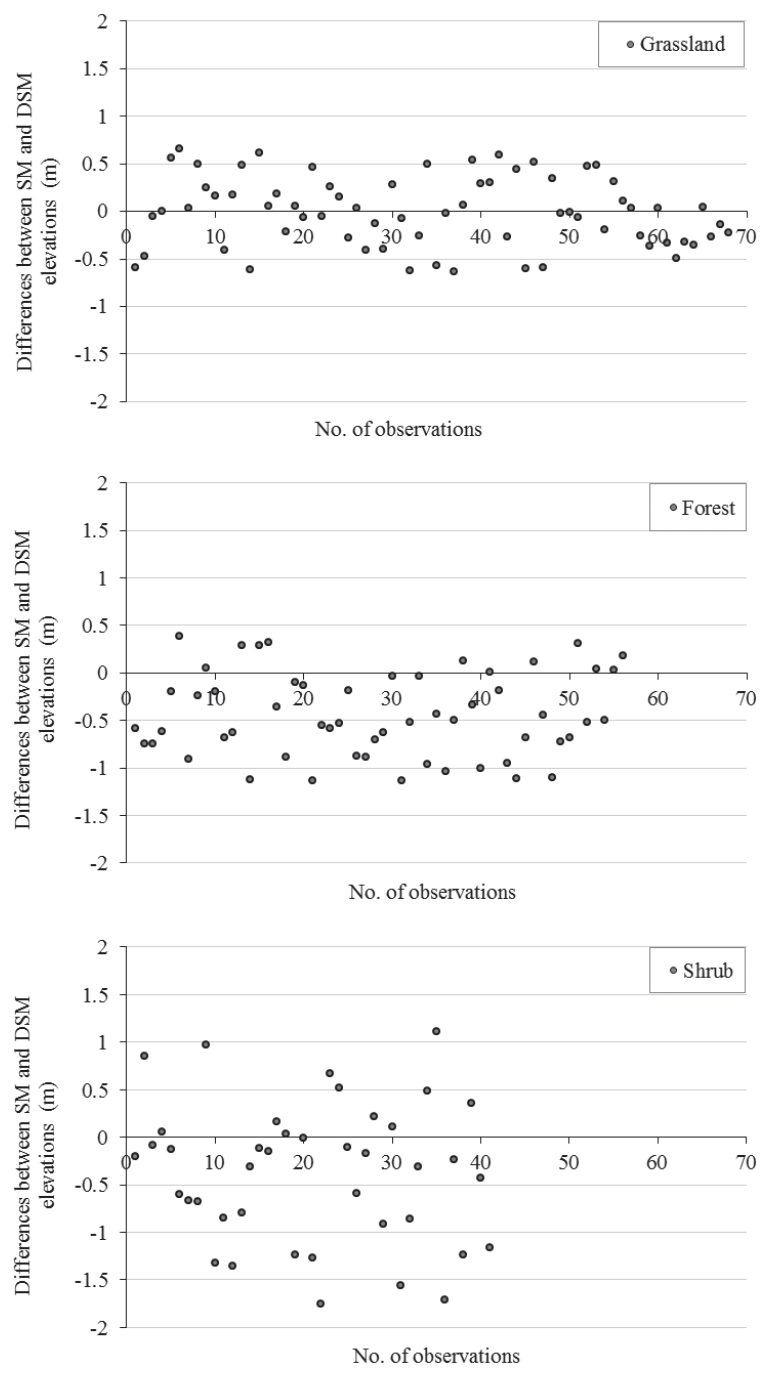

Figure 6. The differences between the elevations obtained by stereo measurements (SM points) and elevations extracted from planimetrically corresponding DSM points

The main lack of such photogrammetrically generated DTM is its questionable accuracy under the forest areas $(2,44)$, especially if additional field data were not collected in order to support (improve) photogrammetric data. On the contrary, due to the possibility of laser light (laser pulses) to penetrate through the tree crowns airborne laser scanning (ALS) sensors are generally well suited to collect ground elevation data for DTM generation even in densely canopied forest stands $(23,45)$. Therefore, the DTM generated from ALS data is of higher accuracy than the photogrammetrically generated $\operatorname{DTM}(10,46)$. Since Croatia is a relatively small country $\left(56542 \mathrm{~km}^{2}\right)$, the ALS data could be collected and processed in considerably short time. Therefore Croatia should follow the example of other European countries (e.g. Austria, Germany, Slovenia, Switzerland, etc.) which conducted or still conduct ALS national flight aerial surveys to collect data for generation high accuracy DTM. Since it can be assumed that the terrain in forest areas does not change significantly over time, the same ALS DTM can be used for longer period of time $(23,33)$. On the other hand, DSM can be updated every several years on the basis of aerial images collected within regular national flight aerial surveys. In that way the same ALS DTM and updated DSMs generated from aerial images enable continuous update of CHMs (33). However, as long as ALS DTM is not available, an existing photogrammetric DTM in combination with high density DSM proposed in this research should be used for the generation of CHM.

The potential of such generated CHM for forestry applications (e.g. estimation of tree height, mean stand height, stand volume, stand biomass, etc.) should be further examined and validated with ground reference data (e.g. measurements from sample plots) following the example of recent worldwide studies (e.g. 11-13, 19-25).

\section{CONCLUSIONS}

Within this research, for the first time in Croatia, an automated image matching procedure was used to generate high density DSM from digital aerial stereo images. The DSM was generated using Dense DTM algorithm of PHOTOMOD software - an area-based image matching algorithm which operates on the principle of cross-correlation approach. The spatial resolution of resulting DSM generated by Dense DTM algorithm corresponds to image pixel size, which was in this case $0.2972 \times 0.2972 \mathrm{~m}$. The good vertical agreement between the generated DSM and stereo measurement was achieved for all three land cover classes present at the research area (grasslands, shrubs, forests). The highest vertical agreement was obtained for the grassland, slightly lower for forest, whereas the lowest vertical agreement was obtained for shrub land cover class. Thus, the results of this research confirmed the results of similar studies which showed that the DSM accuracy depends on land cover class (e.g. 17, 18, 33). Furthermore, the elevations extracted from DSM over forest surface are slightly underestimated compared to the elevations obtained by stereo measurement, which is also in line with the findings of other relevant studies (e.g. 11). In conclusion, the results of this research are very promising and suggest that the high density DSM generated from digital aerial stereo images and by using the proposed methodology has the potential to be used in forestry, primarily in forest inventory. Therefore, further research should be focused on generation of CHM by subtracting available DTM from the high density DSM and on the examination of its potential for deriving various forest attributes.

Acknowledgments: This study has been supported in part by Croatian Science Foundation under the project 2492 (,Estimating and Forecasting Forest Ecosystem Productivity by Integrating Field Measurements, Remote Sensing and 
Modeling"-EFFEctivity) and by Croatian Forest Ltd within the project "The methodology for the damage assessment on forest stands of the Mediterranean caused by extreme natural disasters (fires, wind), recovery and economic measures for minimizing the risk".

\section{REFERENCES}

1. SCHENK T 2005 Introduction to photogrammetry. Department of Civil and Environmental Engineering and Geodetic Science, The Ohio State Universitiy, Columbus, p 95

2. BALENOVIĆ I, SELETKOVIĆ A, PERNAR R, JAZBEC A 2015 Estimation of the mean tree height of forest stands by photogrammetric measurement using digital aerial images of high spatial resolution. Ann Forest Res 58 (1): 125-143 http://dx.doi.org/10.15287/afr.2015.300

3. MAGNUSSON M, FRANSSON J E S, OLSSON H 2007 Aerial photo-interpretation using Z/I DMC images for estimation of forest variables. Scand J Forest Res 22 (3): 254-266

4. LINDER W 2009 Digital photoogrammetry - A practical course. Springer, Berlin, p 220 http://dx.doi.org/10.1007/978-3-54092725-9

5. SANDAU R 2010 Digital airborne camera, introduction and technology. Springer, Dordrecht, p 343 http://dx.doi.org/10.1007/9781-4020-8878-0

6. PERKO R, KLAUS A, GRUBER M 2004 Quality comparison of digital and film-based images for photogrammetric purposes. In: Proceedings of ISPRS - International Society for Photogrammetry and Remote Sensing, p 5

7. HONKAVAARA E, ARBIOL R, MARKELIN L, MARTINEZ L, CRAMER M, BOVET S, CHANDELIER L, ILVES R, KLONUS S, MARSHAL P, SHLÄPFER D, TABOR M, THOM C, VEJE N 2009 Digital airborne photogrammetry - a new tool for quantitiative remote sensing? A state-of-the-art review on radiometric aspects of digital photogrammetric images. Remote Sens 1(3): 577-605 http://dx.doi.org/10.3390/rs1030577

8. LEMMENS M 2011 Digital Photogrammetric Workstations - Status and Features. GIM International 25: 12

9. AWANGE J L, KYALO KIEMA J B 2013 Environmental Geoinformatics - Monitoring and Management. Springer, Berlin, p 541 http://dx.doi.org/10.1007/978-3-642-34085-7

10. WHITE J C, WULDER M A, VASTARANTA M, COOPS N C, PITT D, WOODS M 2013 The utility of image-based point clouds for forest inventory: A comparison with airborne laser scanning. Forests 4 (3): 518-536

11. BALTSAVIAS E, GRUEN A, EISENBEISS H, ZHANG L, WASER L T 2008 High-quality image matching and automated generation of 3D tree models. Int J Remote Sens 29 (5): 1243-1259 http://dx.doi.org/10.1080/01431160701736513

12. ST-ONGE B, VÉGA C, FOURNIER R A, HU Y 2008 Mapping canopy height using a combination of digital stereo-photogrammetry and lidar. Int J Remote Sens 29 (11): 3343-3364

13. NURMINEN K, KARJALAINEN M, YU X, HYYPPÄ J, HONKAVAARA E 2013 Performance of dense digital surface models based on image matching in the estimation of plot-level forest variables. ISPRS J Photogramm 83: 104-115 http://dx.doi.org/10.1016/j.isprsjprs.2013.06.005

14. GEHRKE S, MORIN K, DOWNEY M, BOEHRER N, FUCHS T 2010 Semi-Global Matching: An Alternative to LiDAR for DSM Generation? In: Proceedings of the 2010 Canadian Geomtics Conference and Symposium of Commission I, ISPRS Convergence in Geomatics-Shaping Canada's Competitive Landscape, Calgary, Canada, 15-18 June 2010
15. HONKAVAARA E, MARKELIN L, ROSNELL T, NURMINEN K 2012 Influence of solar elevation in radiometric and geometric performance of multispectral photogrammetry. ISPRS J Photogramm 67: 13-26 http://dx.doi.org/10.1016/j.isprsjprs.2011.10.001

16. VALBUENA R, MAURO F, ARJONILLA F J, MANZANERA J A 2011 Comparing airborne laser scanning-imagery fusion methods based on geometric accuracy in forested areas. Remote Sens Environ 115 (8): 1942-1954 http://dx.doi.org/10.1016/j.rse.2011.03.017

17. POON J, FRASER C S, CHUNSUN Z, LI Z, GRUEN A 2005 Quality assessment of digital surface models generated from IKONOS imagery. Photogramm. Rec 20 (110): 162-171.

18. HOBI M L, GINZLER C 2012 Accuracy Assessment of Digital Surface Models Based on WorldView-2 and ADS80 Stereo Remote Sensing Data. Sensors 12 (5): 6347-6368

19. BOHLIN J, WALLERMAN J, FRANSSON J E S 2012 Forest variable estimation using photogrammetric matching of digital aerial images in combination with a high-resolution DEM. Scand J Forest Res 27 (7): 692-699 http://dx.doi.org/10.1080/02827581.2012.686625

20. JÄRNDSTEDT J, PEKKARINEN A, TUOMINEN S, GINZLER C, HOLOPAINEN M, VIITALA R 2012. Forest variable estimation using a high-resolution digital surface model. ISPRS J Photogramm 74: 78-84 http://dx.doi.org/10.1016/j.isprsjprs.2012.08.006

21. STRAUB C, TIAN J, SEITZ R, REINARTZ P 2013 Assessment of Cartosat-1 and WorldView-2 stereo imagery in combination with a LiDAR-DTM for timber volume estimation in a highly structured forest in Germany. Forestry 86 (4): 463-473

http://dx.doi.org/10.1093/forestry/cpt017

22. VASTARANTA M, WULDER M A, WHITE J C, PEKKARIN EN A, TUOMINEN S, GINZLER C, KANKARE V, HOLOPAINEN M, HYYPPÄ J, HYYPPÄ H 2013 Airborne laser scanning and digital stereo imagery measures of forest structure: Comparative results and implications to forest mapping and inventory update. Can J Remote Sens 39 (5): 382-395

23. GOBAKKEN T, BOLLANDSÅS O M, NÆSSET E 2015 Comparing biophysical forest characteristics estimated from photogrammetric matching of aerial images and airborne laser scanning data. Scand J Forest Res 30 (1): 73-86

24. GRANHOLM A-E, OLSSON A, NILSSON M, ALLARD A, HOLMGREN J 2015 The potential of digital surface models based on aerial images for automated vegetation mapping. Int $J$ Remote Sens 36 (7): $1855-1870$ http://dx.doi.org/10.1080/01431161.2015.1029094

25. STEPPER S, STRAUB C, PRETZSCH H 2015 Assessing height changes in a highly structured forest using regularly acquired aerial image data. Forestry 88 (3): 304-316 http://dx.doi.org/10.1093/forestry/cpu050

26. WASER L T, GINZLER C, KUECHLER M, BALTSAVIAS E 2008 Potential and limits of extraction of forest attributes by fusion of medium point density LiDAR data with ADS40 and RC30 images. In: SilviLaser, 17-19 September 2001, Edinburgh, UK, pp 625-634

27. GRUBER M, PONTICELLIA M, BERNÖGGER S, LEBERL L 2008 Ultracamx, the Large Format Digital Aerial Camera System by Vexcel Imaging/Microsoft. In: Chen J, Jiang J, Baudoin A $(e d s)$ Proceedings of ISPRS XXIst Congress „Silk Road for Information from Imagery", 3-11 July 2008, Beijing. ISPRS, Vol. XXXVII, Part B1, pp 665-670

28. PETRIE G 1997 Developments in digital photogrammetric systems for topographic mapping applications. ITC Journal 2: 121-135

29. BALENOVIĆ I, SELETKOVIĆ A, PERNAR R, MARJANOVIĆ H, VULETIĆ D, PALADINIĆ E, KOLIĆ J, BENKO M 2011 Digital Photogrammetry - State of the Art and Potential for Application in Forest Management in Croatia. South-east Eur for 2 (2): 81-93 http://dx.doi.org/10.15177/seefor.11-09 
30. MCGLONE J C 2013 Manual of photogrammetry. Sixth edition, American Society for Photogrammetry and Remote Sensing, Bethesda, Maryland, USA, p 1318

31. GRUSSENMEYER P, AL KHALIL O 2002 Solutions for Exterior Orientation in Photogrammetry: A Review. Photogramm Rec 17 (100): 615-634

http://dx.doi.org/10.1111/j.1477-9730.2002.tb01907.x

32. HEIPKE C 1997 Automation of interior, relative, and absolute orientation. ISPRS J Photogramm 52 (1) 1-19 http://dx.doi.org/10.1016/S0924-2716(96)00029-9

33. GINZLER C, HOBI M L 2015 Countrywide Stereo-Image Matching for Updating Digital Surface Models in the Framework of the Swiss National Forest Inventory. Remote Sens 7 (4): 4343-4370 http://dx.doi.org/10.3390/rs70404343

34. HÖHLE J, HÖHLE M 2009 Accuracy assessment of digital elevation models by means of robust statistical methods. ISPRS J Photogramm 64 (4): 398-406 http://dx.doi.org/10.1016/j.isprsjprs.2009.02.003

35. SHAPIRO S S, WILK M B 1965 An analysis of variance test for normality (complete samples). Biometrika 52 (3-4): 591-611 http://dx.doi.org/10.1093/biomet/52.3-4.591

36. SHAPIRO S S, WILK M B, CHEN H J 1968 A comparative study of various tests for normality. J Am Stat Assoc 63 (324): 1343-1372 http://dx.doi.org/10.1080/01621459.1968.10480932

37. HILL T, LEWICKI P, 2007 STATISTICS: Methods and Applications. StatSoft, Tulsa, OK

38. BALTSAVIAS E P 1999 A comparison between photogrammetry and laser scanning. ISPRS J Photogramm 54 (2-3): 83-94. http://dx.doi.org/10.1016/S0924-2716(99)00014-3
39. KORPELA I, ANTTILA P 2004 Appraisal of the mean height of trees by means of image matching of digitised aerial photographs. Photogrammetric Journal of Finland 19 (1): 23-36

40. STRAUB C, STEPPER C, SEITZ R, WASER L T 2013 Potential of UltraCamX stereo images for estimating timber volume and basal area at the plot level in mixed European forests. Can J For Res 43 (8): 731-741 http://dx.doi.org/10.1139/cjfr-2013-0125

41. NGUYET D A 2012 Error propagation in carbon estimation using the combination of airborne LIDAR data and very high resolution geo-eye satellite imagery in Ludhikhola watershed, Gorkha, Nepal. PhD Thesis, Enschede, University of Twente Faculty of Geo-Information and Earth Observation (ITC), p 64

42. JENSEN J R 2006 Remote Sensing of the Environment: An Earth Resource Perspective. Second edition, Prentice-Hall, Upper Saddle River, New Jersey, USA p 608

43. MORGAN J L, GERGEL S E, COOPS N C 2010 Aerial photography: A rapidly evolving tool for ecological management. BioScience 60 (1): 47-59 http://dx.doi.org/10.1525/bio.2010.60.1.9

44. BALENOVIĆ I, MARJANOVIĆ H, INDIR K, VULETIĆ D, OSTROGOVIĆ M Z, BENKO M 2013 Estimation of the stands' arithmetic mean diameter using manual method of digital photogrammetry. Period biol 115 (3): 399-407

45. BALENOVIĆ I, ALBERTI G, MARJANOVIĆ H 2013 Airborne Laser Scanning - the Status and Perspectives for the Application in the South-East European Forestry. South-east Eur for 4 (2): 59-79 http://dx.doi.org/10.15177/seefor.13-07

46. VÉGA C, ST-ONGE B 2008 Height growth reconstruction of a boreal forest canopy over a period of 58 years using a combination of photogrammetric and lidar models. Remote Sens Environ 112 (4): 1784-1794 http://dx.doi.org/10.1016/j.rse.2007.09.002 